\title{
Senate House, University of Lagos, Akoka, Nigeria: An Architectural Critique
}

\author{
Oluwadamilola Ajoke Alabi \\ Department of Architecture, Bells University of Technology, Ota, Nigeria
}

Email address:

damilolaalabi12@gmail.com

To cite this article:

Oluwadamilola Ajoke Alabi. Senate House, University of Lagos, Akoka, Nigeria: An Architectural Critique. American Journal of Art and Design. Vol. 5, No. 1, 2020, pp. 12-16. doi: 10.11648/j.ajad.20200501.12

Received: April 24, 2020; Accepted: May 18, 2020; Published: June 17, 2020

\begin{abstract}
This study is an architecture critique using graphics and verse to provide an understand of the architecture of the senate building of University of Lagos in order to logically create an awareness of the intensity and extent of the feelings created by building. It was designed by James Cubitt Architects and was completed in 1986. The study gives a description of the building's concept, features and environments. An analysis of the conceptual elements was made and these elements are wall, platform, columns and facades. Also, studies of the effects of modifying elements of light, colour, temperature and ventilation, sound, texture, and time were made. The approach used to carry out the study is architectural criticism using the principles discussed in 'Analysing Architecture', a book by Simon Unwin. Findings from the study revealed that the architecture of Senate House was iconic and modern with attractive expressions of the African culture. This was generated in line with the design firm's philosophy and the client's brief. Also, the beauty of the building is enhanced by the varying heights and forms making it a likely inspiration to tertiary institutions seeking the use of timeless and impressionable architecture which would interpret intellectual desires and values of their citadels of learning.
\end{abstract}

Keywords: Architecture, Criticism, Descriptive Criticism, Senate, University of Lagos

\section{Introduction}

Sparse studies have been carried out to study the architecture of buildings in Nigeria. Hence, the understanding of these works of architecture is not deep. Studies on architecture in Nigeria can be carried out through architectural criticism so as to elicit deeper understanding of them. Architecture criticism can be carried out using ten different methods which can be classified into three fundamental groups $[1,2]$. These groups are narrative, interpretive and descriptive evaluation. The use of descriptive criticism helps to create an understanding of work of architecture (upon experiencing it) by making use of facts [3]. Descriptive criticism can be carried out through the depictive evaluation method where static and dynamic descriptions of these buildings' form and structure using images and words are used. Works of architecture carried out in Nigeria are growing in number. An understanding of these works is very important as these pieces are potential sources of design inspiration to architecture designers who experience them. Unfortunately, few studies exist that are directed towards assisting with the creation/establishment of an understanding of architecture in Nigeria. This study picks up an iconic symbol of the University of Lagos, Akoka and presents an in-depth descriptive criticism making use of the depictive evaluation method. It is hoped that this critique will provide a clearer picture of a symbolic work of architecture in Nigeria which defines a place.

\section{Background}

The senate building of the University of Lagos, Akoka in Lagos State, Nigeria, was designed by the Nigerian based British practice James Cubitt Architects and construction was completed in 1986. The site was originally a busy thoroughfare and the architect had the challenge of creating the impression of not robbing the community of an important route. A second test faced by the designer was the need to create a large, imposing and unique corporate head office which would not make the vicinity look congested but livened and light. These demands were however welcomed by the architectural practice as their 
self-acclaimed strength lies in the ability to 'translate every brief into simple, precise, yet bold forms, with a commitment to social and environmental responsibility' [4]. To achieve the client's brief, Messrs James Cubitt settled on adopting principles of modern architecture which was just awakening in Nigeria at the time and infusing it with touches of African elements thus creating a pleasing, aesthetically appealing and functional cocktail of architecture. Tenets of modern architecture adopted were the flat roof, raised platform, clean lines and horizontality. African elements infused were the cylindrical form and patterns created with the façade and mosaic tiles.

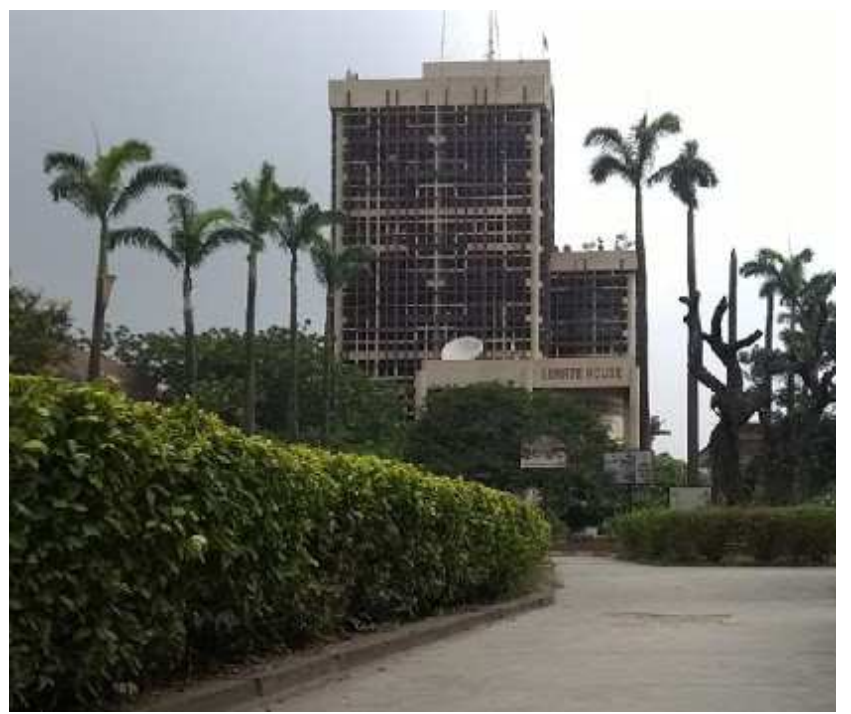

Figure 1. The University of Lagos' 'seat of power' [5].

\section{Method}

The study is a case with which observation technique was employed. The building was experienced by the researcher and images of the building were taken in order to express observations. To provide an understanding, architectural criticism was logically carried out using the depictive evaluation method. Various guides exist, however, the principles expressed by [6] were used.

\section{Finding}

\subsection{Intellectual Structure}

The building is located at a vantage and central focal point on the University of Lagos main campus. It is surrounded by the Social Science Faculty, newly constructed Art Gallery, Old Senate Chambers, Akintunde Ojo Memorial Library and the Main Auditorium. There is a 'one way' street flowing past the rear of the building (which had originally cut through the building site) while a forecourt (Senate garden) occupies the frontage of the structure. This forecourt is wide and dotted with tall trees encased with concrete seats. It serves not just as a pause for staff and students but also as a pedestrian concourse.

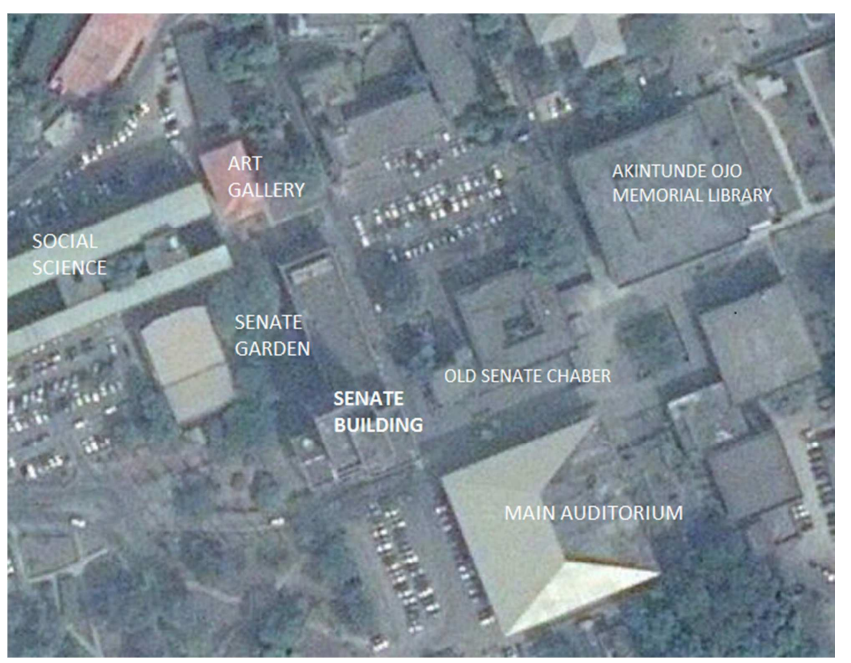

Figure 2. Satellite image of Senate House, University of Lagos [7].

The structure's form is a combination of simple forms consisting of intersecting cuboids piercing a cylinder, the beauty of it which was enhanced with projections of varying heights. The building can be viewed clearly from all sides especially because of the two tallest projections which act as markers. However, physical approach to the structure is mainly from the narrow ends.

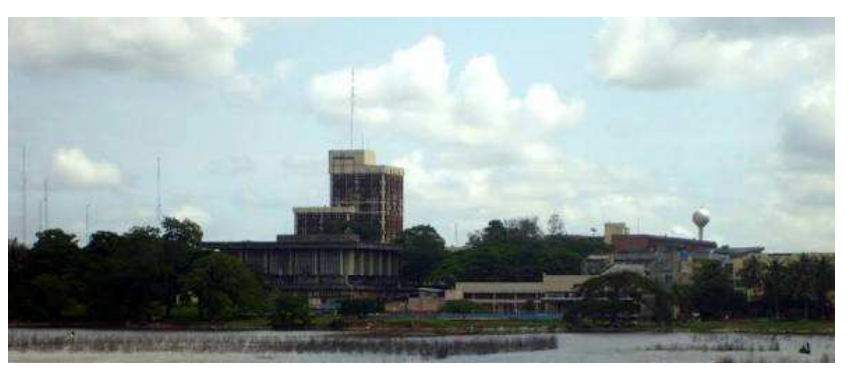

Figure 3. The Senate House can easily be seen within a 1 kilometre radius [8].

The fundamental purpose of the building was to provide a structure which would portray a corporate image of the university and emphasize the uniqueness of the 'seat of power' [8]. It has done this by using its form to pull the eye of all within approximately a kilometre radius to shun other buildings and focus first on its majestic form.

\subsection{Conceptual Elements}

The primary architectural elements of Unilag Senate House are wall, platform, columns and façade [6]. Key functional spaces of the building start from the first floor (platform). Thus, the building uses the piloting system where the ground floor is open and occupied mainly by stairs leading to the first floor and support columns embedded in reception and security stations. The ground undulates with steps synchronizing with the changing levels. The soffit of the platform is approximately 4 meters above the ground floor datum and is textured with a waffle pattern. 


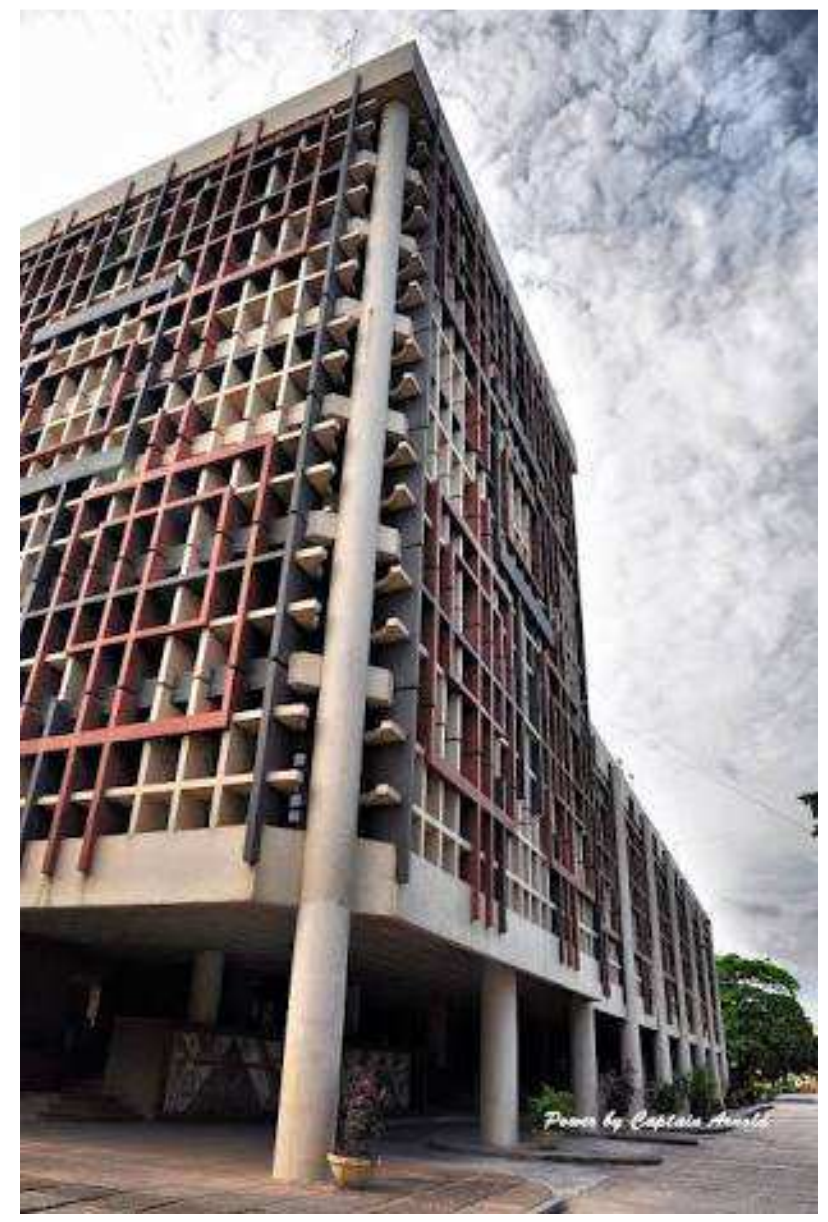

Figure 4. Note the platform, column arrangement and effect of the facade on building texture [9].

Following the perimeter of the building are bold and undisguised cylindrical columns spaced at equal intervals forming a peristyle [6]. Hanging between the columns from the last floor and terminating at the first-floor datum and following the external walls of the multi-levelled intersecting cuboids, is a lace-like concrete façade. This façade is a weave of evenly spaced vertical and horizontal lines with a seemingly unpredictable configuration which upon a closer study reveals a definite pattern visible only when each elevation is perceived fully. The façade masks the external walls which sit on stanch projections of the floor slab, are non-load bearing and pierced with rows of alternate windows per floor.

The uniformity of the building's exterior is broken by a prominent curved wall located at the eastern corner of the first floor. This forms a cell with a double volume height primarily designed to function as the senate chamber. The wall is slashed with narrow, vertical windows and is capped with a flat and square roof which is supported at all ends and midsections with the same bold cylindrical columns viewed on the rest of the building's perimeter.

\subsection{Modifying Elements}

\subsubsection{Light}

Between the hours of $7 \mathrm{am}$ and $5 \mathrm{pm}$, natural light is filtered through the windows behind the concrete façade creating a stimulating effect on the administrative staff while sufficiently lighting the offices for basic administrative activities. However, artificial lights become supporting elements. The cell (senate chamber) and corridors rely heavily on artificial light as this form of light is controlled in order to precisely produce the desirable guidance and adequate lighting for the University's 'Power Room'. At night, when the internal lights come on, the building looks like a shaded lamp because of the filter pattern created by the external façade.

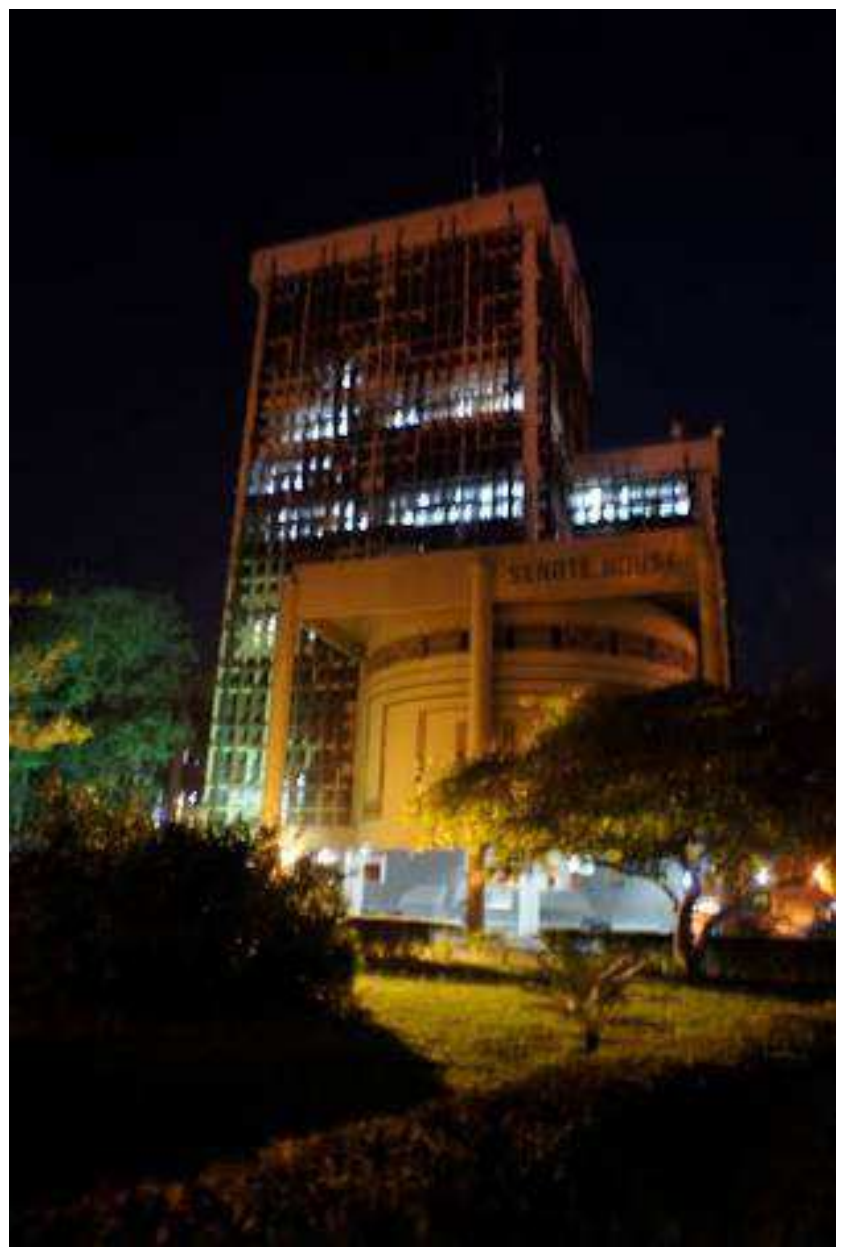

Figure 5. The building lights up like a shaded lamp at night [10].

A welcoming shade from the tropical sun is offered by the trees dotting the concourse at the foreground of the Senate House. This is further complimented by the inviting shade on the ground floor. This lends a feeling of relief which counteracts the intimidating feel built up while approaching the structure.

\subsubsection{Colour}

A most striking feature apart from the imposing size and dramatic façade of Senate House is the beautiful and artistic use of earth-toned colours ranging from cream to deep brown. The colours are used to give the building a strong ethnic African undertone reminiscence of African royalty. Coloured mosaic tiles and textured paint propose to the mind 
a well patterned arrangement of beads and a veil synonymous with veiled African royalty. This is because in most African cultures, the royal class wear identification beads and subjects are forbidden to look directly into their eyes. The creative choice of colours also produces a sense of awe, captures the attention and generates curiosity.

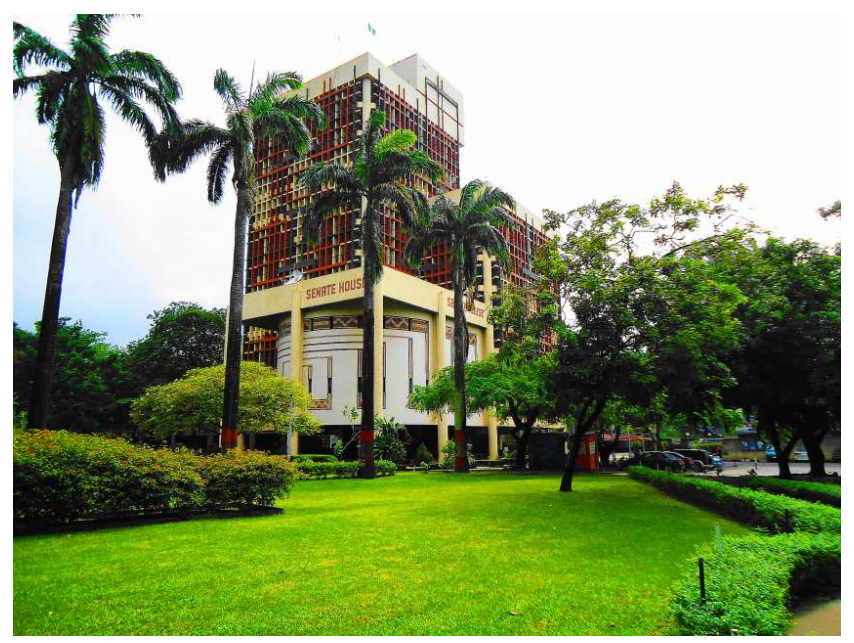

Figure 6. The earth toned colors add an ethnic feel to the building's aura [11].

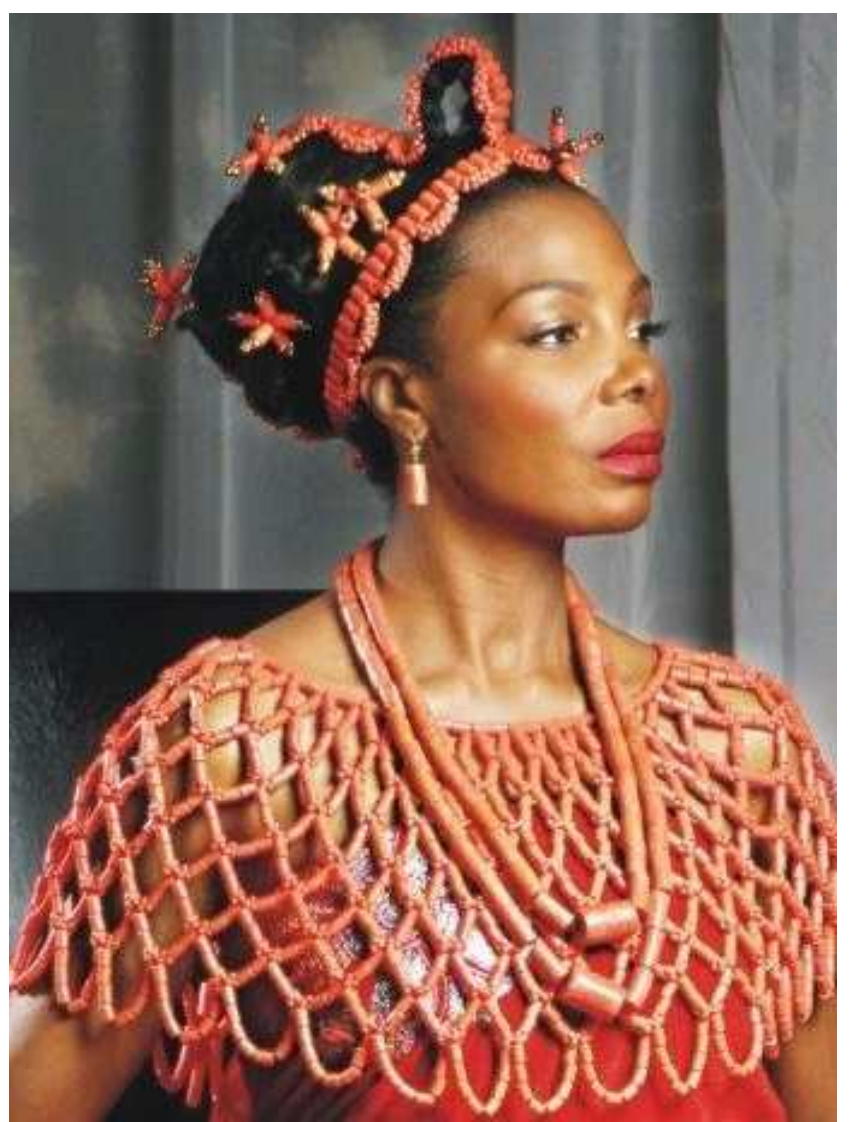

Figure 7. Image of a beaded African [12].

\subsubsection{Temperature and Ventilation}

The orientation of the building is done such that the longest unbroken face (i.e. rear) easily and fully receives air coming from the north-east. The front face receives air flowing from the south-west. As the impact of the southwest wind is experienced more due to the tropical climatic conditions of Lagos and also because this wind can move at great speeds, a projection at the north end and the grove of trees dotting the concourse breaks and slows down the air, reducing the weathering impact of driving rain carried by this wind. Advantage of natural ventilation through a cooling updraft generated by the air sucked in from the ground floor flowing upwards through the staircases to the upper floors and the use of large windows which admit air is also achieved. The constant flow of natural air cools the building down sufficiently keeping its occupants comfortable.

\subsubsection{Sound}

The building is bombarded with noisy sounds from its front and rear as pedestrians flow the length of the front while vehicles ply the length of its rear on Otunba Payne Drive. To absorb these distracting sounds, the structure is made mostly of concrete and the strategically positioned trees also play a significant role in the absorption of sound, the foliage of trees are excellent sound absorbers [13-15]. This is because their leaves are layered and soft therefore increasing the quality of catching and absorbing sound. Also, tree trunks do not encourage reflection of sound as their surfaces are rough. A moderately dense collection of trees is planted at the senate garden. Palm trees are planted in rows lining the drive leading to and around the senate building. Dense shrubs also line this drive-in formal manner. This vegetation absorbs quite some sound from passing vehicles and pedestrians.

\subsubsection{Texture}

One of the outstanding characteristics of this iconic structure is its texture. Surrounded with structures exhibiting smooth rendered walls and fair-face concrete, the weave of the building's exterior gives it a character totally different from the others. Seemingly emphatically speaking out loud, "I am different!" This noticeable difference in texture pulls the eye and make the building look more special than those surrounding it. Thus, giving the building a quality of more prestige over the others.

\subsubsection{Time}

The effect of time on the building is synonymous to the quality of aging wine. External appearance of Senate House does not show the damaging effect of time. This is likely due to the choice of colours which hide the presence of settled dust and the mosaic tiles which are self-cleaning requiring minimum maintenance activity. Sadly, the 'Nigerian' maintenance culture does not favour frequent maintenance procedures [16] and this self-cleaning character gives the structure a head and shoulders distinction on building quality maintenance with minimal effort.

\section{Conclusion}

In retrospect, the Architects, Messrs James Cubit, did 
justice to the desires of University of Lagos, by translating their brief into a piece of functional and artistic architecture [6]. Unilag Senate House is a positive iconic image of the university and can stand the test of time in terms of acceptable quality architecture. Hence, the structure should be an inspiration to other tertiary institutions seeking the use of timeless and impressionable architecture to interpret intellectual desires and values of their citadels of learning.

\section{References}

[1] Attoe, W. (1978). Architecture and Criticism. New York: John Wiley \& Sons.

[2] Ramon, P., \& Coyne, R. (2000). The production of Architectural Criticism. Architectural Theory Review.

[3] Uji, Z. (1994). Philosophy of the Creative Process in Architecture. Jos: Zuruck Nigeria Limited.

[4] JamesCubittArchitects. (2012). James Cubitt Architects. Retrieved January 28, 2016, from http://jamescubitt.com

[5] Gadsta. (2016). Gadsta. Retrieved January 2016, from Gadsta Web site: http://www.gadsta.com

[6] Unwin, S. (2007). Analysing Architecture. London: Routledge.

[7] Googleearth. (2016). Googleearth. Retrieved June 10, 2016, from Googleearth Web site: http://www.Googleearth.com

[8] Joephobe. (2012). Joe Phoebe. Retrieved January 28, 2016, from Joe Phoebe Web site: http://www.joephobe.com
[9] Skysrapercity. (2016). skysrapercity. Retrieved January 2018, 2016, from Skysrapercity Wbe site: http://www.skysrapercity.com

[10] Wordpress. (2016). fullandbright.wordpress. Retrieved January 28, 2016, from Fullandbright Wordpress Web site: http://fullandbright.wordpress.com

[11] Awomodu, G. (2016). Wordpress. Retrieved January 28, 2016, from Wordpress Web site: http://gbengaawomodu.wordpress.com

[12] Pintrest. (2019). Beaded African. Retrieved January 15, 2020, from Pintrest Web site: http://pintrest.com

[13] Coder, K. D. (2011). Identified Benefits of Community Trees \& Forestsby - Community Forest Series. Georgia: Warnell.

[14] Killicoat, P., Puzio, E., \& Stringer, R. (2002). The Econmic Value of Trees in Urban Areas: Estimating the Benefits of Adelaide's Street Trees. Treenet Proceedings of the 3rd National Street Tree Symposium: 5th and 6th September 2002 ISBN 0-9775084-2-0 Treenet Inc- School of Economics and Centre for International Economic Studies (pp. 1-14). Adelaide: University of Adelaide.

[15] Landscapingnetwork. (2016). Landscapingnetwork. Retrieved May 15, 2019, from Landscaping Network Web site: https://www.landscapingnetwork.com/landscape-design/noisereduction.html

[16] Tijani, S. A., Adeyemi, A. O., \& Omotehinshe, O. J. (2016). Lack of Maintenance Culture in Nigeria: The Bane of National Development. Civil and Environmental Research IISTE, VIII (8), 23-30. 